\title{
Value of Protein C and D-Dimer in Predicting Non Hepatocellular Carcinoma Portal Vein Thrombosis in Patients with Liver Cirrhosis
}

\author{
Sahar A. El-Nemr ${ }^{1}$, Sherief M. Galal ${ }^{1}$, Hoda Abd-El-Aziz El-Hady ${ }^{2}$, \\ Naglaa Ali Khalifa ${ }^{3}$ \\ Departments of Tropical Medicine ${ }^{1}$, Internal Medicine ${ }^{2}$ and Clinical Pathology ${ }^{3}$, \\ Faculty of Medicine, Zagazig University,Egypt.
}

Corresponding Author Sahar A. El-Nemr

Mobile:

$+201007246450$

\section{E} mail:alnimrsahar@ya hoo.com

\section{Key words:}

Liver cirrhosis, Portal vein thrombosis $(P V T)$, Protein $C(P C), D$ dimer
Background and study aim: Patients with liver cirrhosis may develop serious changes of coagulation process. Protein $\mathrm{C}$ (PC) is synthesized in the liver and considered as the key component of an important natural anticoagulant pathway. D-dimer is a fibrin degradation product that represents an accurate marker of fibrinolytic activity. Advances in imaging techniques have resulted in $5-27 \%$ increase in patients with liver cirrhosis being diagnosed with portal vein thrombosis (PVT). The aim of this study was to estimate the value of plasma levels of protein $\mathrm{C}$ and $\mathrm{D}$-dimer as predictors for diagnosis of PVT in patients with liver cirrhosis.

Patients and methods: This study included one hundred cirrhotic patients who underwent abdominal ultrasound and dynamic contrast enhanced computed tomography (CT) scans. Therefore, they were classified into two groups as following: Group 1: Included twenty six patients (22 males and 4 females, mean age 53.60 \pm 7.8 years) with PVT and Group 2: Included seventy four patients (65 males and 9 females, mean age $54.96 \pm 6.5$ years) without PVT as a control group. Full history taking, complete physical examinations and laboratory investigations including liver

\section{INTRODUCTION}

The liver plays a vital role in the coagulation process as it synthesizes and metabolizes the majority of fibrinolytic factors, as well as most proteins which favour and inhibit the process of coagulation and fibrinolysis [1]. Liver failure may disrupt the haemostatic system and decreased levels of most procoagulant factors, leading to severe bleeding or thrombotic function tests, complete blood count, prothrombin time (PT), activated partial thromboplastin time (aPTT), International Normalizing Ratio (INR) and determination the levels of plasma protein C and Ddimer were done for all cirrhotic patients.

Results: The levels of D-dimer were significantly higher in cirrhotic patients with PVT than in those patients without PVT, while the level of protein $C$ were significantly lower in cirrhotic patients with PVT than the control group. Also, Ddimer was significantly increased from Child-Pugh class A to C, while PC was significantly progressively decreased. Ddimer cut-off values above $530 \mathrm{ng} / \mathrm{L}$ provided high sensitivity and negative predictive value $(92.3 \%$ and $95.7 \%$, respectively). Also, PC cut-off values below $71.6 \%$ had a high sensitivity and negative predictive value $(96.2$ and $96.9 \%$, respectively).

Conclusion: PVT formation in liver cirrhosis is closely associated with decreased plasma levels of PC, and increased D-dimer. So, they are considered risk factors in PVT formation in patients with liver cirrhosis. So, estimation of plasma levels of protein $\mathrm{C}$ and D-dimer are important for early detection of PVT in patients with liver cirrhosis.

complications [2]. However, decreased levels of the procoagulants are accompanied by decreases in levels of such naturally occurring anticoagulants as antithrombin III and protein C $[\mathbf{3 , 4}]$.

Protein $\mathrm{C}(\mathrm{PC})$ is a major physiological anticoagulant that is synthesized in the liver, circulates in plasma and is considered a key component of an 
important natural anticoagulant pathway $[\mathbf{5 , 6 ]}$. It is vitamin $\mathrm{K}$-dependent serine protease enzyme that is activated by thrombin into activated protein $\mathrm{C}$ (APC), and the treatment with vitamin $\mathrm{K}$ antagonists might further reduce the level of this naturally occurring anticoagulant in patients with liver cirrhosis, increasing the risk of thrombosis [5].

D-dimer is a Fibrin degradation product (FDP) that represents an accurate marker of fibrinolytic activity [7]. D-dimer concentrations are routinely determined in the differential diagnosis of venous thromboembolism, including deep vein thrombosis and pulmonary embolism [8,9]. In addition, Ddimer concentrations increase with deteriorating liver function and may be associated with PVT [10].

Portal vein thrombosis (PVT) is more commonly seen in end-stage liver disease [11] and may be associated with sclerotherapy, abdominal surgery or hepatocellular carcinoma (HCC) $[\mathbf{1 2 , 1 3}]$. Lifethreatening complications such as refractory ascites, upper gastrointestinal bleeding and intestinal ischemia and necrosis can occur in patients with PVT [14]. Therefore, it is necessary to develop efficient methods for detecting PVT, in order to allow earlier diagnosis, treatment and avoid serious complications.

The present study aimed to estimate the value of plasma levels of protein C and D-dimer as predictors for diagnosis of PVT in patients with liver cirrhosis.

\section{PATIENTS AND METHODS}

This study was conducted in the Tropical Medicine, Internal Medicine and Clinical Pathology Departments, Faculty of Medicine, Zagazig University Hospitals in the period from tune 2014 to July 2015. It included 100 cirrhotic patients. They underwent abdominal ultrasound and dynamic contrast enhanced computed tomography (CT) scans. Therefore, they were classified into two groups as following:

Group 1 (PVT group): It included twenty six cirrhotic patients (22 males and 4 females, mean age 53.60 \pm 7.8 years) were diagnosed with PVT.

Group 2 (control group): it included seventy four cirrhotic patients (65 males and 9 females, mean age $54.96 \pm 6.5$ years) without PVT.

\section{Exclusion criteria:}

- Patients suffering from malignancy or any blood diseases.
- Known and recent discovered patients with HCC by triphasic CT with and without elevated alpha fetoprotein.

- Patients receiving anti-coagulant or antiplatelet medications.

- Endoscopic therapy; splenectomy; autoimmune disease; liver cirrhosis due to autoimmune hepatitis or primary biliary cirrhosis.

- Patients having positive rheumatoid factor, trauma, pregnancy, recent surgery, infection or dehydration.

- Diabetes, hypertension, renal disorder, malabsorption.

All patients were subjected to:

- Thorough history taking

- Full physical examination

- Routine laboratory investigations as liver function tests (LFT), kidney function tests (KFT), complete blood picture.

- Prothrombin time (PT), activated partial thromboplastin time (aPTT) levels were determined by routine coagulation methods with the coagulation detector, using a Sysmex CA6000 automated analyser (Sysmex, Milton Keynes, UK).

- Special investigations:

- Estimation of plasma protein C: The protein $\mathrm{C}$ antigen assay was done by a sandwich ELISA [15].

\section{Reference ranges:}

- Protein C antigen values are generally expressed in relative percent as compared to pooled normal plasma. The reference range when normal plasma samples were tested by the Helena protein $\mathrm{C}$ antigen assay was $72-160 \%$ (mean, $110 \%$ and SD, $24 \%$ ).

- Determination of D-dimer: Using automated VIDAS D-dimer exclusion II [16].

Reference ranges: The normal range (up to $500 \mathrm{ng} / \mathrm{ml}$ )

- Abdominal ultrasound: Using Aloka SSD200 (a $3.5 \mathrm{MHz}$ transducer).

- Dynamic contrast enhanced computed tomography (CT) scans : To estimate the vessel patency within the portal venous system, including intrahepatic portal vein branches, main portal vein, superior mesenteric vein, 
and splenic vein. PVT was appeared as a filling defect in the CT images [17].

- The diagnosis of liver cirrhosis based on the clinical examination, laboratory tests, imaging tests, and liver biopsy or fibroscan if present.

- Severity of the liver disease was scored according to Child-Pugh classification.
(Table I), and patients were classified as class A, class B or class $\mathrm{C}$, using parameter of serum bilirubin, serum albumin, prothormbin time (PT) or International Normalizing Ratio (INR), hepatic encephalopathy and ascites [18].

Table (I): Child-Pugh-Turcotte criteria

\begin{tabular}{|l|c|c|c|}
\hline & 1 Point & 2 Points & 3 Points \\
\hline Albumin (g/dl) & $>3.5$ & $2.8-3.5$ & $<2.8$ \\
\hline Bilirubin (mg/dL) & $<2$ & $2-3$ & $>3$ \\
\hline Ascites & None & Minimal & Moderate \\
\hline Encephalopathy & None & Grade 1-2 & Grade 3-4 \\
\hline PT (second prolonged) & $<4$ & $4-6$ & $>6$ \\
INR & $<1.7$ & $<1.7-2.3$ & $>2.3$ \\
\hline
\end{tabular}

PT; prothormbin time INR, International Normalizing Ratio

Class A: 5-6 points; class B: 7-9 points; class C: 10-15 points

\section{Statistical analysis}

Continuous variables were expressed as the mean $\pm \mathrm{SD}$ and the categorical variables were expressed as a number (percentage). Continuous variables were checked for normality by using ShapiroWilk test. Independent Student t-test was used to compare two groups of normally distributed data. Percent of categorical variables were compared using Pearson's Chi-square test. Receiver operating characteristic (ROC) curve analysis was used to identify optimal cut-off values of D-dimer and protein $\mathrm{C}$ with maximum sensitivity and specificity for prediction of portal vein thrombosis. Area Under Curve (AUROC) was also calculated, criteria to qualify for AUC were as follows: $0.90-1=$ excellent, $0.80-0.90=$ good, $0.70-0.80=$ fair; $0.60-0.70=$ poor; and $0.50-0.6=$ fail. The optimal cut-off point was established at point of maximum accuracy. All tests were two sided. $\mathrm{P}<0.05$ was considered statistically significant. All data were analyzed using Statistical Package for Social Science for windows version 18.0 (SPSS Inc., Chicago, IL, USA) \& MedCalc for windows version 13 (MedCalc Software bvba, Ostend, Belgium).

\section{RESULTS}

Results are shown in the following tables :

Table (1): Demographic data of studied groups.

\begin{tabular}{|l|c|c|c|}
\hline \multicolumn{1}{|c|}{ Demographic data } & $\begin{array}{c}\text { PVT group } \\
(\mathbf{N = 2 6 )}\end{array}$ & $\begin{array}{c}\text { Control group } \\
(\mathbf{N = 7 4 )}\end{array}$ & P-value \\
\hline Age (years) & $53.6 \pm 7.8$ & $54.9 \pm 6.5$ & $0.407 *$ \\
\hline Gender & $22(84.6 \%)$ & $65(87.8 \%)$ & $0.737 \S$ \\
Male & $4(15.4 \%)$ & $9(12.2 \%)$ & $0.967 \S$ \\
Female & $3(11.5 \%)$ & $10(13.5 \%)$ & \\
\hline Child classification & $14(53.8 \%)$ & $39(52.7 \%)$ & \\
A (n=13) & $9(34.6 \%)$ & $25(33.8 \%)$ & \\
B (n=53) & C $(n=34)$ & & \\
\hline
\end{tabular}

$\mathrm{N}=$ Total number of patients in each group; Quantitative data were expressed as mean \pm 1SD; Qualitative data were expressed as a number (percentage); * Independent samples Student's t-test; $\S$ Chi-square test; $\mathrm{P}<0.05$ is significant. 
Table (2): Levels of platelet, prothrombin time, activated partial thromboplastin time, D-dimer and protein $\mathrm{C}$ as regard Child class.

\begin{tabular}{|l|c|c|c|}
\hline \multirow{2}{*}{\multicolumn{1}{|c|}{ Parameters }} & \multicolumn{3}{|c|}{ Child-Pugh classification } \\
\cline { 2 - 4 } & $\begin{array}{c}\mathbf{A} \\
(\mathbf{N = 1 3})\end{array}$ & $\begin{array}{c}\mathbf{B}^{*} \\
(\mathbf{N}=\mathbf{5 3})\end{array}$ & $\begin{array}{c}\mathbf{C}^{*} \\
(\mathbf{N}=\mathbf{3 4})\end{array}$ \\
\hline Platelet count $\left(\mathrm{x} 10^{3} / \mathrm{mm}^{3}\right)$ & $106.4 \pm 11.3$ & $82.9 \pm 12.3^{\circ}$ & $79.5 \pm 21.2^{*}$ \\
\hline PT $($ seconds) & $13.9 \pm 0.9$ & $16.9 \pm 1.9^{\circ}$ & $18.9 \pm 2.5^{*}$ \\
\hline APPT (seconds) & $30.6 \pm 3.1$ & $31.7 \pm 5.2$ & $42.2 \pm 12.2^{*}$ \\
\hline Protein C $(\%)$ & $73.6 \pm 16$ & $65.9 \pm 9.6^{\circ}$ & $64 \pm 10.3^{\circ}$ \\
\hline D-dimer $((\mu / \mathrm{ml})$ & $436.6 \pm 80$ & $890.4 \pm 103^{\circ}$ & $927.5 \pm 165^{\circ}$ \\
\hline
\end{tabular}

PLT, platelet; PT, prothrombin time; aPTT, activated partial thromboplastin time;

$\mathrm{N}=$ Total number of patients in each group; Quantitative data were expressed as mean $\pm 1 \mathrm{SD}$; Independent samples Student's t-test; $\mathrm{P}<0.05$ is significant; $\S \mathrm{P}<0.05$ versus group $\mathrm{A}, \bullet \mathrm{P}<0.001$ versus group $\mathrm{A}, \# \mathrm{P}<0.05$ versus group $B, \$ P<0.001$ versus group $B$.

Table (3): Comparison between the studied groups as regards levels of platelet, prothrombin time, activated partial thromboplastin time, D-dimer and protein C.

\begin{tabular}{|l|c|c|c|}
\hline \multicolumn{1}{|c|}{ Parameters } & $\begin{array}{c}\text { PVT group } \\
(\mathbf{N = 2 6})\end{array}$ & $\begin{array}{c}\text { Control group } \\
(\mathbf{N = 7 4 )}\end{array}$ & P-value \\
\hline Platelet (PLT) count $\left(\times 10^{3} / \mathrm{mm}^{3}\right)$ & $89.4 \pm 28.7$ & $91.2 \pm 21.8$ & $0.740^{*}$ \\
\hline PT (seconds) & $16.1 \pm 3.8$ & $15.6 \pm 3.7$ & $0.557^{*}$ \\
\hline APPT (seconds) & $35.4 \pm 5.8$ & $35.9 \pm 5.4$ & $0.691^{*}$ \\
\hline Protein C $(\%)$ & $62.6 \pm 7.2$ & $72.3 \pm 6.5$ & $<0.001^{*}$ \\
\hline D-dimer $((\mu / \mathrm{ml})$ & $980.6 \pm 112$ & $534.2 \pm 94.9$ & $<0.001^{*}$ \\
\hline
\end{tabular}

$\mathrm{N}=$ Total number of patients in each group; Quantitative data were expressed as mean $\pm 1 \mathrm{SD} ; *$ Independent samples Student's t-test; $\mathrm{P}<0.05$ is significant.

Table (4): Levels of platelet, prothrombin time, activated partial thromboplastin time, D-dimer and protein C in PVT group versus control group in different Child class

\begin{tabular}{|c|c|c|c|c|c|c|c|c|c|}
\hline \multirow[b]{2}{*}{ Parameters } & \multicolumn{3}{|c|}{ Child A } & \multicolumn{3}{|c|}{ Child B } & \multicolumn{3}{|c|}{ Child C } \\
\hline & $\begin{array}{l}\text { PVT } \\
\text { group } \\
(\mathbf{N}=3)\end{array}$ & \begin{tabular}{|c|} 
Contro \\
group \\
$(\mathrm{N}=10)$ \\
\end{tabular} & $\begin{array}{c}\mathbf{P} \\
\text { value }\end{array}$ & $\begin{array}{c}\text { PVT } \\
\text { group } \\
(\mathrm{N}=14)\end{array}$ & $\begin{array}{c}\text { Control } \\
\text { group } \\
(\mathbf{N}=39)\end{array}$ & $\begin{array}{c}\mathbf{P} \\
\text { value }\end{array}$ & \begin{tabular}{|c|} 
PVT \\
group \\
$(\mathrm{N}=9)$
\end{tabular} & $\begin{array}{l}\text { Control } \\
\text { group } \\
(\mathrm{N}=\mathbf{2 5})\end{array}$ & $\begin{array}{c}\mathbf{P} \\
\text { value }\end{array}$ \\
\hline $\begin{array}{l}\text { Platelet count } \\
\left(\times 10^{3} / \mathrm{mm}^{3}\right)\end{array}$ & $\begin{array}{c}99.6 \pm \\
23.2\end{array}$ & $\begin{array}{c}106.7 \pm \\
26.5\end{array}$ & $0.685^{*}$ & $\begin{array}{c}104.4 \pm \\
14.2\end{array}$ & $\begin{array}{c}109.7 \pm \\
16.5\end{array}$ & $0.291 *$ & \begin{tabular}{|c|}
$59.3 \pm$ \\
9.2 \\
\end{tabular} & $\begin{array}{c}66.3 \pm \\
12.5\end{array}$ & 0.04 \\
\hline $\mathrm{PT}(\mathrm{s}$ & $\begin{array}{c}13.9 \pm \\
0.3\end{array}$ & $\begin{array}{c}14.0 \pm \\
0.8\end{array}$ & $0.840 *$ & $\begin{array}{c}16.4 \pm \\
0.6\end{array}$ & $\begin{array}{c}16.4 \pm \\
0.8\end{array}$ & $1.000 *$ & $\begin{array}{c}18.9 \pm \\
0.6\end{array}$ & $\begin{array}{c}18.4 \pm \\
0.8\end{array}$ & 0.02 \\
\hline APP & $\begin{array}{c}29.9 \pm \\
3.3 \\
\end{array}$ & $\begin{array}{c}30.1 \pm \\
4.1\end{array}$ & $0.940 *$ & $\begin{array}{c}31.9 \pm \\
4.3\end{array}$ & $\begin{array}{c}30.1 \pm \\
3.1\end{array}$ & $0.099 *$ & $\begin{array}{c}39.9 \pm \\
3.2\end{array}$ & $\begin{array}{c}40.1 \pm \\
2.1\end{array}$ & 0.80 \\
\hline Prote & $\begin{array}{c}69.9 \pm \\
10.1\end{array}$ & $\begin{array}{c}72.9 \pm \\
8.2\end{array}$ & $0.605^{*}$ & $\begin{array}{c}58.9 \pm \\
9.1\end{array}$ & $\begin{array}{c}66.6 \pm \\
8.0\end{array}$ & $0.004 *$ & $\begin{array}{c}60 \pm \\
6.5\end{array}$ & $\begin{array}{c}64.1 \pm \\
4.0\end{array}$ & 0.01 \\
\hline D-d & $\begin{array}{c}434 \pm \\
28\end{array}$ & $\begin{array}{c}415 \pm \\
29\end{array}$ & $0.338^{*}$ & $\begin{array}{c}875 \pm \\
18\end{array}$ & $\begin{array}{c}759 \pm \\
19\end{array}$ & $<0.001 *$ & $\begin{array}{c}980 \pm \\
25\end{array}$ & $\begin{array}{c}825 \pm \\
21\end{array}$ & $<0.0$ \\
\hline
\end{tabular}

$\mathrm{N}=$ Total number of patients in each group; Quantitative data were expressed as mean $\pm 1 \mathrm{SD} ; *$ Independent samples Student's t-test; $\mathrm{P}<0.05$ is significant. 
Table (5): Validity of D-dimer and protein $\mathrm{C}$ in prediction of portal vein thrombosis in all cirrhotic patients; ROC curve analysis

\begin{tabular}{|l|c|c|c|c|c|c|}
\hline \multicolumn{1}{|c|}{$\begin{array}{c}\text { Cut-off } \\
\text { values }\end{array}$} & $\begin{array}{c}\text { SN \% } \\
(\mathbf{9 5 \%} \mathbf{C I})\end{array}$ & $\begin{array}{c}\text { SP \% } \\
(\mathbf{9 5 \%} \mathbf{C I})\end{array}$ & $\begin{array}{c}\text { PPV \% } \\
(\mathbf{9 5 \%} \mathbf{C I})\end{array}$ & $\begin{array}{c}\text { NPV \% } \\
(\mathbf{9 5 \%} \mathbf{C I})\end{array}$ & $\begin{array}{c}\text { Accuracy } \\
(\mathbf{9 5 \%} \text { CI })\end{array}$ & $\begin{array}{c}\text { AUROC } \\
(\mathbf{9 5 \%} \text { CI })\end{array}$ \\
\hline $\begin{array}{l}\mathrm{D}-\text { dimer } \\
>530 \mathrm{ng} / \mathrm{L}\end{array}$ & $\begin{array}{c}92.3 \% \\
(73.8-100)\end{array}$ & $\begin{array}{c}59.5 \% \\
(25.5-93.5)\end{array}$ & $\begin{array}{c}44.4 \% \\
(10-78.8)\end{array}$ & $\begin{array}{c}95.7 \% \\
(81.6-100)\end{array}$ & $\begin{array}{c}68.0 \% \\
(35.7-100)\end{array}$ & 0.7 \\
\hline $\begin{array}{l}\text { Protein C } \\
<71.6 \%\end{array}$ & $96.2 \%$ & $41.9 \%$ & $36.8 \%$ & $96.9 \%$ & $56.0 \%$ & 0.6 \\
$(83-100)$ & $(7.7-76.1)$ & $(3.4-70.2)$ & $(84.9-100)$ & $(21.6-90.4)$ & \\
\hline
\end{tabular}

ROC curve: Receiver Operating Characteristic curve; SN: Sensitivity; SP: Specificity; PPV: Positive Predictive Value; NPV: Negative Predictive Value; 95\%CI: 95\% Confidence Interval; AUROC: Area Under Receiver Operating Characteristic curve.

\section{DISCUSSION}

Portal vein thrombosis (PVT) is one of the severe complications of liver cirrhosis [19,20]. It is more commonly seen in end-stage liver disease and particularly in those who have HCC [11]. It may lead to hemorrhage of the gastrointestinal tract, intestinal ischemia or refractory ascites, and could even be life-threatening [13]. So, early diagnosis and treatment of PVT in patients with liver cirrhosis may save lives.

The prevalence of PVT in the present study was high $(26 \%)$. However, many studies proved that the advanced imaging techniques have resulted in 5-27\% of patients with liver cirrhosis being diagnosed with PVT $[\mathbf{1 0 , 2 1 , 2 2 ]}$ and others reported that prevalence of PVT ranges from $0.6 \%$ to $26 \%$ in liver cirrhosis $[\mathbf{1 9 , 2 0}]$.

The liver plays an important role in the coagulation process as it synthesizes and metabolizes the majority of fibrinolytic factors, as well as proteins which favour and inhibit the process of coagulation and fibrinolysis. Liver failure may disrupt the haemostatic system, leading to severe bleeding or thrombotic complications [1,2].

This study found that PT and aPTT were significantly prolonged with the deterioration of liver function from Child-Pugh class A to C, but did not correlate with the formation of PVT. The coagulation function of cirrhotic patients was generally suppressed due to their hepatic failure, which is usually reflected as decreased coagulants. So, they considered as important parameters in indicating liver dysfunction $[\mathbf{1 0 , 1 5}]$.

The results showed significantly progressive decreasing of PLT that correlated with the stages of liver dysfunction. These results can be explained as PLT counts were decreased possibly from hypersplenism, decreased production of thrombopoietin synthesis in the liver $[\mathbf{1 0 , 2 3}]$.
Protein C (PC) is a major physiological anticoagulant. The thrombin-thrombomodulin complex activates PC, which inhibits the blood coagulation cascade by selective degradation of the procoagulant factors Va and VIIIa $[5,12]$.

In the current study plasma protein $\mathrm{C}$ concentrations were found to be decreased significantly with deteriorating liver function, such that both ChildPugh class B and class C patients had significantly lower protein $\mathrm{C}$ concentrations than class $\mathrm{A}$. So that protein $\mathrm{C}$ activity may be used as a sensitive marker of hepatocellular damage [2].

Moreover, plasma PC levels in the PVT group were significantly lower than those in the control group. One of the underlying mechanisms may be due to the fact that hepatocytes fail to synthesize adequate amounts of PC under ischemic and hypoxic conditions. Also, the decrease in PC may be attributed to the endothelial cells damage caused by portal hypertension, which leads to the activation and subsequent consumption of PC in fibrolytic processes [10].

D-dimer is a fibrin degradation product, a small protein fragment present in the blood after a blood clot is degraded by fibrinolysis [7]. It is a sensitive marker of coagulation and fibrinolysis. Hyperfibrinolysis in cirrhotic patients might represent a state of low grade disseminated intravascular coagulation $[\mathbf{2 4 , 2 5 ]}$.

In this study, D-dimer levels were significantly increased from Child-Pugh class A to $\mathrm{C}$ so, it was found to have significant correlations with liver dysfunction. Also, D-dimer in the PVT group was significantly higher than this in the control group [26].

The sensitivity, specificity, positive and negative predictive values for PVT of PC and D-dimer in liver cirrhosis patients was calculated. The Ddimer cut-off values were above $530 \mathrm{ng} / \mathrm{L}$ and PC cut-off values were below $71.6 \%$. Those cut- 
off values provided a sensitivity of $92.3 \%$ and $96.2 \%$, a negative predictive value of $95.7 \%$ and $96.9 \%$, for D-dimer and PC respectively, so decreased PC and increased D-dimer values can suspect the presence of PVT $[\mathbf{1 0 , 2 6 ]}$.

\section{CONCLUSION}

The previous data concluded that disturbed coagulation in patients with liver cirrhosis is directly related to the severity of cirrhosis and more importantly, it showed that decreased PC and increased D-dimer values were the risk factors in PVT formation. Therefore, they can suspect the presence of PVT and then specific imaging techniques should be done to confirm the diagnosis and initiate early treatment before the occurrence of serious complications.

\section{RECOMMENDATIONS}

Although both coagulation and anticoagulation systems in cirrhotic patients are suppressed as a result of the functional failure of the liver, the two systems may still be maintained. Therefore, there is no tendency for hemorrhage or thrombosis under stable conditions. When cirrhotic patients present under stress, such as sepsis, trauma or scheduled for operative interference, the balance between the two systems is disturbed and those patients should be screened for both coagulation and anticoagulation systems to be managed accurately.

Plasma transfusion (with its contents of coagulant and antithrombotic factors) might be used in particular postoperative decompensation in chronic liver disease patients.

Antithrombotic therapy can be used for recanalization of the portal vein in PVT patients, but evidence for the safety and efficiency of anticoagulants in PVT patients is still lacking and need proper study.

Ethical approval: Approved.

Funding: None.

Conflict of interest: Authors declare no conflict of interest related to this article.

\section{REFERENCES}

1-Tripodi A, Anstee QM, Sogaard KK, Primignani M, Valla DC. Hypercoagulability in cirrhosis: causes and consequences. J Thromb Haemost 2011; 9: 1713-1723.
2- Saray A, Mesihovic R, Vanis N, Gornjakovic S, Prohic D. Clinical significance of haemostatic tests in chronic liver disease. Med Arch 2012; 66: 231-5.

3- Tripodi A. Hemostasis abnormalities in chronic liver failure. In: Gines P, Kamath PS, Arroyo V, eds. Chronic liver failure: Mechanisms and management. New York: Springer 2010; 289-303.

4- Saray A, Mesihovic R, Vanis N, Amila M. Protein C Deficiency in Chronic Hepatitis C: Correlation With Histological Extent of Liver Fibrosis. Clin Appl Thromb Hemost. 2015 May 24. pii: 1076029615587356.

5- Dahlback B , Villoutriex BO. Regulation of blood coagulation by the PC anticoagulant pathway. Art Thromb Vasc Biol 2005; 25: 1311-20.

6- Nicolaes GA, Dahlbäck B. Congenital and acquired activated protein $\mathrm{C}$ resistance. Semin. Vasc. Med 2003; 3 (1): 33-46.

7- Pabinger I, Ay C. Biomarkers and venous thromboembolism. Arterioscler Thromb Vasc Biol 2009; 29: 332-336.

8- Anderson DR, Wells PS, Stiell I, MacLeod B, Simms M, Gray L et al. Management of patients with suspected deep vein thrombosis in the emergency department: combining use of a clinical diagnosis model with D-dimer testing. J Emerg Med 2000; 19: 225-230.

9- Wells PS, Anderson DR, Rodger M, Forgie M, Kearon C, Dreyer J et al. Evaluation of D-dimer in the diagnosis of suspected deep-vein thrombosis. $N$ Engl J Med 2003; 349: 1227-1235.

10- Zhang D, Hao J, Yang N. Protein C and D-dimer are related to portal vein thrombosis in patients with liver cirrhosis. J Gastroenterol Hepatol 2010; 25: 116-121.

11- Singhal A, Karachristos A, Bromberg M, Daly E, Maloo M, Jain AK. Hypercoagulability in endstage liver disease: prevalence and its correlation with severity of liver disease and portal vein thrombosis. Clin Appl Thromb Hemost 2012; 18 : 594-598.

12- Mangia A, Villani MR, Cappucci G, Santoro R, Ricciardi R, Facciorusso D et al. Causes of portal venous thrombosis in cirrhotic patients: the role of genetic and acquired factors. Eur $J$ Gastroenterol Hepatol 2005; 17: 745-751.

13- Alkim H, Ayaz S, Sasmaz N, Oguz P, Sahin B. Hemostatic abnormalities in cirrhosis and tumorrelated portal vein thrombosis. Clin Appl Thromb Hemost 2012; 18: 409-415.

14- Amitrano L, Guardascione MA, Brancaccio V, Iannaccone L, Ames PR, Balzano A. Portal and mesenteric venous thrombosis in cirrhotic patients. Gastroenterology 2002; 123:1409-1410. 
15- Griffin LC, Tidmarsh GF, Bock LC, Toole JJ, Leung LL. In vivo anticoagulant properties of a novel nucleotide-based thrombin inhibitor and demonstration of regional anticoagulation in extracorporeal circuits. Blood 1993; 81(12):32716.

16- Agarwal S, Joyner KA Jr, Swaim MW. Ascites fluid as a possible origin for hyperfibrinolysis in advanced liver disease. Am J Gastroenterol 2000; 95:3218-3224.

17- Qi X, Han G, He C Yin Z, Guo W, Niu J, Fan D. CT features of non-malignant portal vein thrombosis: a pictorial review. Clin Res Hepatol Gastroenterol. 2012; 36:561-8.

18- Pugh RN, Murray-Lyon IM, Dawson JL, Pietroni MC, Williams R. Transection of the oesophagus for bleeding oesophageal varices. Br J Surg 1973; 60: 646-9.

19- Congly SE, Lee SS. Portal vein thrombosis: Should anticoagulation be used? Curr Gastroenterol Rep 2013; 15:306-13.

20- Ponziani FR, Zocco MA, Garcovich M, D'Aversa F, Roccarina D, Gasbarrini A. What we should know about portal vein thrombosis in cirrhotic patients: A changing perspective. World $J$ Gastroenterol 2012;18:5014-20.

21- Amitrano L, Guardascione MA, Brancaccio V, Margaglione M, Manguso F, Iannaccone L et al. Risk factors and clinical presentation of portal vein thrombosis in patients with liver cirrhosis. $J$ Hepatol 2004; 40: 736-741.
22- Francoz C, Belghiti J, Vilgrain V Sommacale D, Paradis V, Condat B et al. Splanchnic vein thrombosis in candidates for liver transplantation: usefulness of screening and anticoagulation. Gut 2005; 54: 691-7.

23-Okubo M, Shiota G, Kawasaki H. Thrombopoietin levels in serum and liver tissue in patients with chronic viral hepatitis and hepatocellular carcinoma. Clin. Sci. 2000; 99: 207-14.

24- Piscaglia F, Donati G, Giannini R, Bolondi L. Liver cirrhosis, ascites, and hyperfibrinolysis. Am J Gastroenterol. 2001;96:3222.

25- Spadaro A, Tortorella V, Morace C, Spadaro A, Tortorella V, Morace C et al. High ciruclating Ddimers are associated with ascites and hepatocellular carcinoma in liver cirrhosis. World J Gastroenterol. 2008;14: 1549-1552.

26- Zhang DL, Hao JY, Yang N. Value of D-dimer and protein $\mathrm{S}$ for diagnosis of portal vein thrombosis in patients with liver cirrhosis. $J$ Int Med Res 2013; 41:664-72.

Peer reviewer: Mostafa Elshamy, Professor of Tropical Medicine and Hepatogastroenterology, Faculty of Medicine, Zagazig University, Egypt. Editor: Tarik Zaher, Professor of Tropical Medicine and Hepatogastroenterology, Faculty of Medicine, Zagazig University, Egypt 